\title{
Hsa_circ_0032463 acts as the tumor promoter in osteosarcoma by regulating the miR-330-3p/PNN axis
}

\author{
GUANGHUA QIN and XUEJIAN WU
}

Department of Orthopedics, The First Affiliated Hospital of Zhengzhou University, Zhengzhou, Henan 450000, P.R. China

Received October 14, 2020; Accepted February 25, 2021

DOI: $10.3892 / \mathrm{ijmm} .2021 .4925$

\begin{abstract}
Osteosarcoma (OS), also known as bone cancer, is a threat to the lives of millions of adolescents worldwide. Although dedicated efforts have been invested in reducing the mortality rate of this bone cancer, the research community is yet to find the exact causes of OS. Thus, the present research aimed to study the association between circular RNA circ_0032463 and OS progression. The impact of circ_0032463 on cells with OS was first evaluated using reverse transcription-quantitative PCR. This evaluation was followed by the assessment of cell proliferation, viability, apoptosis, invasion and adhesion using BrdU, Cell Counting Kit-8, flow cytometry, Transwell and cell adhesion assays, respectively. RNA pull-down, RNA immunoprecipitation chip and dual-luciferase reporter systems were utilized to investigate the relationship between circ_0032463,microRNA (miR)-330-3p and Pinin desmosome associated protein (PNN) in OS. The findings indicated that circ_0032463 and PNN were highly expressed in OS tissues and OS cell lines, and that they facilitated cell proliferation, viability, invasion and adhesion, but attenuated cell apoptosis in OS cells. The low expression of miR-330-3p suppressed OS development. It was also noted that circ_0032463 inhibited miR-330-3p to upregulate PNN expression. In conclusion, this study confirmed that by regulating the miR-330-3p/PNN axis, circular RNA circ_0032463 could function as a tumor enhancer in cells with OS.
\end{abstract}

\section{Introduction}

Osteosarcoma (OS) refers to a form of bone cancer that affects the knee or other ends of the long bones (1). This malignancy is rare among most demographics, but it is more common among children and adolescents (2). Although physicians have used surgery, chemotherapy and radiotherapy to ameliorate

Correspondence to: Dr Xuejian Wu, Department of Orthopedics, The First Affiliated Hospital of Zhengzhou University, 1 Jianshe Dong Road, Zhengzhou, Henan 450000, P.R. China

E-mail: xuejian_wu36@163.com

Key words: circular RNA_0032463, microRNA-330-3p, Pinin desmosome associated protein, osteosarcoma the debilitating symptoms of this bone cancer, the survival rate of OS is still not satisfactory (3). Recent progress achieved in molecular genetic research of OS has improved the understanding of OS development (4). Nonetheless, further research is needed to identify the underlying molecular mechanism of this tumor and reduce the survival rate of OS (5).

Circular RNAs (circRNAs) consist of closed-loop polymeric molecules that are crucial to the expression and regulation of genes (6). Unlike RNAs, circRNAs have their $3^{\prime}$ and 5 ' terminals joined, and they can inactivate microRNAs (miRNAs/miRs) by regulating the biological function of genes in eukaryotes (7). Emerging studies have demonstrated the crucial roles of circRNAs in OS (8-10). In one previous study, it was reported that a high level of circ-ITCH in OS cells facilitated the spread of OS by enhancing EGFR phosphorylation (11). Another previous report documented that the negative effect of circ_0008792 on OS samples was highly pronounced (12). However, to the best of our knowledge, the effects of circ_0032463 on OS cells has not yet been explored.

In contrast to circRNAs, miRNAs cannot code genes. However, miRNAs can degrade or inhibit the transcription of mRNAs by binding to specific regions of the target genes (13). In recent years, researchers have documented the ability of miRNAs to influence the progression of various cancers by targeting protein-coding genes and regulating mRNA expression (14-16). Some miRNAs function as tumor promoters in OS development, including miR-299-5p, miR-765 and miR-624-5p (17-19). Other miRNAs can act as tumor suppressors in OS progression, such as miR-375, miR-224-3p and miR-627-3p (20-22). As for miR-330-3p, some studies have reported on the inhibitory role of this miRNA in carcinogenesis $(23,24)$. A recent study found that miR-330-3p inhibited tumor progression by suppressing polycomb complex protein Bmi-1 (Bmi-1) expression in OS (25). Nonetheless, researchers are yet to confirm whether miR-330-3p could be regulated by circ_0032463 in OS.

Pinin desmosome associated protein ( $\mathrm{PNN}$ ) is a protein-coding gene, which is associated with a number of diseases, such as melanoma and Volkmann ischemic contracture (26). The high expression of PNN has been found to facilitate ovarian carcinoma (27), colorectal cancer (28) and hepatocellular carcinoma (29). However, its role in OS is yet to be confirmed.

The present research aimed to investigate whether novel circRNA (circ_0032463) could accelerate or inhibit OS 
progression. It was hypothesized that circ_0032463 promoted OS by inhibiting miR-330-3p and upregulating PNN expression. Regardless of the outcome of the hypothesis, the findings of this study could provide novel insights into OS treatments.

\section{Materials and methods}

Bioinformatics analysis. The GSE96964 dataset (https://www. ncbi.nlm.nih.gov/geo/query/acc.cgi?acc=GSE96964) from the Gene Expression Omnibus (GEO) database is a circRNA expression profile that was selected to screen the upregulated circRNAs in OS samples with $\mathrm{P}<0.05$ and log fold-change $(\mathrm{FC})>1$. GSE16088 (30) and GSE12865 (31) datasets, also from the GEO database, are mRNA expression profiles that were selected to screen the upregulated genes in OS samples with $\mathrm{P}<0.05$ and $\log \mathrm{FC}>1$. The Search Tool for the Retrieval of Interacting Genes/Proteins (STRING; https://string-db.org/) was used to analyze the key biological process for the upregulated genes. CircInteractome (https://circinteractome.nia.nih.gov/index.html) was utilized to predict the miRNAs sponged by key circRNAs, whereas starBase (http://starbase.sysu.edu.cn/panCancer.php) and TargetScan (http://www.targetscan.org/vert_71/) were utilized to predict the miRNAs that target the key genes.

Tissue collection and cell culture. Tissue samples with and without OS were obtained from 13 patients who underwent surgery between January 2018 and December 2019 at The First Affiliated Hospital of Zhengzhou University (Zhengzhou, China). The inclusion criteria included patients who were diagnosed with OS and had not received preoperative radiotherapy, chemotherapy or other adjuvant treatments, whereas the exclusion criteria included patients who were diagnosed with other diseases and did not sign the informed consent. The experimental procedure was approved by the Ethics Committee of the First Affiliated Hospital of Zhengzhou University (approval no. ChiECRCT20200309), and informed consent was obtained from the patients before they could participate in the experiment. The characteristics of the participants with OS are presented in Table I. All cell lines used in this study were obtained from the American Type Culture Collection, including the human fetal osteoblast cell line (hFOB1.19) and human OS cell lines (HOS, U2OS, Saos-2 and SOSP-9607). The cells were maintained in an RPMI-1640 medium (Invitrogen; Thermo Fisher Scientific, Inc.) supplemented with $10 \%$ FBS (Gibco; Thermo Fisher Scientific, Inc.) and $1 \%$ penicillin-streptomycin (Gibco; Thermo Fisher Scientific, Inc.), and they were incubated in an atmosphere containing $5 \% \mathrm{CO}_{2}$ at $37^{\circ} \mathrm{C}$.

Cell transfection. To explore the function of circ_0032463, miR-330-3p and PNN in OS, the OS cells were divided into eight groups: i) short hairpin RNA (sh-) negative control (NC) group; ii) sh-circ_0032463 group; iii) miR-mimics group; iv) NC mimics group; v) miR-inhibitor group; vi) $\mathrm{NC}$ inhibitor group; vii) sh-circ_0032463 + miR-inhibitor group; and viii) sh-PNN + miR-inhibitor group. The sh-circ_0032463, miR-330-3p inhibitor, miR-330-3p mimic, sh-PNN and negative control (NC) plasmids were purchased from Shanghai GenePharma Co., Ltd. The sequences of all plasmids used in this study are listed in Table SI. The transfections with the shRNAs, miRNA mimic, inhibitor or corresponding NCs into Saos-2 and U2OS cells $\left(1 \times 10^{5}\right)$ were performed using Lipofectamine ${ }^{\circledR} 3000$ reagent (Invitrogen; Thermo Fisher Scientific, Inc.) at $37^{\circ} \mathrm{C}$ for $48 \mathrm{~h}$. Next, $100,1,000$ or $2,500 \mathrm{ng}$ shRNAs were transfected into the cells seeded into a 96-, 12- or 6-well plate, respectively. Then, 3, 30 or 75 pmol miR-330-3p mimic or inhibitor were seeded into a 96-, 12- or 6-well plate, respectively.

Reverse transcription-quantitative (RT-q)PCR. Total RNA was extracted from the OS tissues and cells (Hfob1.19, HOS, U2OS, Saos-2 and SOSP-9607) with TRIzol ${ }^{\circledR}$ reagent (Invitrogen; Thermo Fisher Scientific, Inc.). According to the manufacturer's protocols, the HiScript II Q RT SuperMix (Vazyme Biotech Co., Ltd.) was employed for circRNA and PNN mRNA reverse-transcription, the miRNA 1st Strand cDNA Synthesis kit (Vazyme Biotech Co., Ltd.) was used to prepare miR-330-3p. Then, RT-qPCR analysis was performed with the SYBR Green PCR Master Mix kit (Thermo Fisher Scientific, Inc.). The thermocycling conditions were as follows: Initial denaturation at $95^{\circ} \mathrm{C}$ for $10 \mathrm{~min}, 40$ cycles of denaturation at $95^{\circ} \mathrm{C}$ for $10 \mathrm{sec}$, annealing and extension at $60^{\circ} \mathrm{C}$ for $1 \mathrm{~min}$. The $2^{-\Delta \Delta \mathrm{Cq}}$ method (32) was then used to analyze the changes in gene expression. The reference control for mRNA and circRNA was GAPDH, while that for miRNA was U6. The primer sequences are presented in Table II. After incubating $1 \mathrm{mg}$ RNA for $30 \mathrm{~min}$ at $37^{\circ} \mathrm{C}$, RNase R (Epicentre; Illumina, Inc.) was utilized to validate the stability of circRNA. The RNA was then utilized to synthesize cDNA for RT-qPCR.

Isolation of cytoplasmic and nuclear fractions. The separation of the cytoplasmic and nuclear RNA in the UOS and Saos-2 cells was performed with the PARIS ${ }^{\mathrm{TM}}$ kit (Thermo Fisher Scientific, Inc.). The cells were subsequently gathered and lysed with the cell fractionation buffer. After centrifugation at $4^{\circ} \mathrm{C}$ and $10,000 \mathrm{xg}$ for $2 \mathrm{~min}$, the supernatant with cytoplasmic fraction and the sediment with nuclear fraction were added to the lysis/binding solution and an equal volume of ethanol. After filtering the mixture, the elution buffer was used to elute the RNA from the cytoplasmic and nuclear fractions. U6 snRNA and GAPDH rRNA were used as the reference controls for nuclear fraction and cytoplasmic fraction, respectively. The extracted RNA expression of circ_0032463 and linear gene signal-induced proliferation-associated 1-like protein 1 (SIPA1L1) was estimated with RT-qPCR.

BrdU assay. The UOS and Saos- 2 cells were seeded into the 96-well plates at a density of $1 \times 10^{5}$ cells/well. The BrdU Cell Proliferation Assay kit (Frdbio Bioscience \& Technology) was then used to evaluate the proliferative ability of the cells transfected for $48 \mathrm{~h}$. This was performed according to the manufacturer's protocols. After the cell culture medium was eliminated, the cell fixation solution $(100 \mu \mathrm{l})$ was transferred to each well to fix the cells at room temperature for $30 \mathrm{~min}$. Next, the solution was dried, and the cell denaturation solution $(100 \mu \mathrm{l})$ was added to each well for denaturation at $20-22^{\circ} \mathrm{C}$ for $10 \mathrm{~min}$. Following which, the washing solution $(300 \mu \mathrm{l})$ was used to wash the cells three times. The BrdU antibody $(100 \mu \mathrm{l})$ was then added to each well to incubate the cells for 
Table I. Clinical characteristics of 13 patients with osteosarcoma.

\begin{tabular}{lc}
\hline Characteristics & Number of patients, $\mathrm{n}(\%)$ \\
\hline Total & 13 \\
Sex & \\
Male & $7(53.85)$ \\
Female & $6(46.15)$ \\
Age, years & \\
$<12$ & $1(7.69)$ \\
$12-29$ & $7(53.85)$ \\
$30-49$ & $3(23.08)$ \\
$\geq 50$ & $2(15.38)$ \\
Tumor size, cm & \\
$\leq 12$ & $8(61.54)$ \\
$>12$ & $5(38.46)$ \\
TNM stage (49) & \\
I-II & $10(76.92)$ \\
III-IV & $3(23.08)$ \\
Site & \\
Extremities & $9(69.23)$ \\
Other & $4(30.77)$ \\
Distant metastasis & \\
Negative & $9(69.23)$ \\
Positive & $4(30.77)$ \\
\hline
\end{tabular}

TNM, tumor node metastasis.

$1 \mathrm{~h}$ at $37^{\circ} \mathrm{C}$. Subsequently, $100 \mu \mathrm{l}$ diluted HRP-labeled goat anti-mouse antibody from the BrdU Cell Proliferation Assay kit was added to each well, and the mixture was incubated for another $1 \mathrm{~h}$ at $37^{\circ} \mathrm{C}$. The TMB substrate solution was added, and the mixture was incubated at $20-22^{\circ} \mathrm{C}$ for $10 \mathrm{~min}$. Finally, $100 \mu \mathrm{l}$ substrate termination solution was added to each well, and the optical density at $450 \mathrm{~nm}$ was read with a microplate reader (BioTek Instruments, Inc.).

Cell Counting Kit-8 (CCK-8) assay. A CCK-8 Kit (Dojindo Molecular Technologies, Inc.) was employed to identify the viability of cells. The OS cells $\left(1 \times 10^{5}\right)$ were plated in a 96 -well plate. For each period $(0,24,48,72$ and $96 \mathrm{~h})$, the CCK-8 solution $(10 \mu \mathrm{l} /$ well) was added to the OS cells and cultured in the dark for another $2 \mathrm{~h}$. The optical absorbance at $450 \mathrm{~nm}$ was measured with a microplate reader.

Cell apoptosis detection. A flow cytometry system and Annexin V-FITC/PI apoptosis detection kit (Shanghai Yeasen Biotechnology Co., Ltd.) were employed to assess cell apoptosis. The transfected cells $\left(1 \times 10^{6}\right)$ were gathered and then cleaned twice with precooled PBS. This was followed by the addition of binding buffer $(100 \mu \mathrm{l})$ to the resuspended cells. The PI staining solution (10 $\mu \mathrm{l})$ and Annexin V-FITC (5 $\mu \mathrm{l})$ were added, and the cells were incubated in the dark for $10 \mathrm{~min}$. Following which, the cell apoptosis rate was detected for $1 \mathrm{~h}$ using a BD FACSCalibur flow cytometer (BD Biosciences), and was analyzed using FlowJo 7.6.1 (FlowJo LLC). The percentage of late apoptotic
Table II. Primer sequences for reverse transcription-quantitative PCR.

\begin{tabular}{|c|c|}
\hline Genes & Primer sequences $\left(5^{\prime} \rightarrow 3^{\prime}\right)$ \\
\hline circ_0032463 & $\begin{array}{l}\text { F: } \text { GCCCAGCCTTTGAAGAATTT } \\
\text { R: TTCTGTGGTTGCCATAATCC }\end{array}$ \\
\hline circ_0097271 & $\begin{array}{ll}\text { F: } & \text { CTGTGGAAACCCTTGGTTGT } \\
\text { R: } & \text { TCACCTGTGAGAATTGACTGG }\end{array}$ \\
\hline circ_0113706 & $\begin{array}{ll}\mathrm{F}: & \text { ACACCCTTCTCATGGCAATC } \\
\mathrm{R}: & \text { CAAATGGCCCAAАTCATTGT }\end{array}$ \\
\hline circ_0111388 & $\begin{array}{ll}\mathrm{F}: & \text { TCCTTATCAACCCCACCAAA } \\
\text { R: } & \text { TGGCAAGTTCTTTTTCACAGG }\end{array}$ \\
\hline circ_0012726 & $\begin{array}{ll}\mathrm{F}: & \text { ACTTCTCCACGGTTTCAAGC } \\
\text { R: } & \text { CTGCAATCCACAGATGAAGC }\end{array}$ \\
\hline circ_0136823 & $\begin{array}{l}\mathrm{F}: \text { AACCCAAGACCCCGAAAG } \\
\text { R: GCAGTGTCAGGCAAAGTCTG }\end{array}$ \\
\hline circ_0113185 & $\begin{array}{ll}\mathrm{F}: & \text { CATGGGGAAGGCTATGTGAA } \\
\mathrm{R}: & \text { CCTTCAAGAAGCCAGAGGTG }\end{array}$ \\
\hline miR-330-3p & $\begin{array}{ll}\text { F: } & \text { CAACTGCCTCTCTGGGCCTG } \\
\text { R: } & \text { CTGCAGAGAGGCAGCGCTG }\end{array}$ \\
\hline PNN & $\begin{array}{l}\text { F: GGCTTGTTGATGGGTACCCTT } \\
\text { R: GCTGCGCAAGCTCAACTTTCT }\end{array}$ \\
\hline GAPDH & $\begin{array}{l}\mathrm{F}: \text { CCACATCGCTCAGACACCAT } \\
\text { R: CCAGGCGCCCAATACG }\end{array}$ \\
\hline U6 & $\begin{array}{l}\text { F: CGCTTCGGCAGCACATATAC } \\
\text { R: TTCACGAATTTGCGTGCAT }\end{array}$ \\
\hline
\end{tabular}

F, forward; R, reverse; circ, circular RNA; miR, microRNA; $\mathrm{PNN}$, Pinin desmosome associated protein.

cells is presented in Q1-UR, whereas the percentage of early apoptotic cells is presented in Q1-LR.

Transwell assay. The Corning ${ }^{\circledR}$ BioCoat $^{\mathrm{TM}}$ Matrige $^{\circledR}$ Invasion Chambers (Corning, Inc.) were used to measure cell invasion. The transfected cells $\left(1 \times 10^{5}\right.$ cells/well) were inoculated in the upper Transwell chambers in serum-free RPMI-1640 medium (Invitrogen; Thermo Fisher Scientific, Inc.). RPMI-1640 with $10 \%$ FBS, was included in the lower Transwell chambers to establish a chemical attractant. After $48 \mathrm{~h}$ of incubation at $37^{\circ} \mathrm{C}$, cells in the upper chambers that had not invaded were swabbed away. Invaded cells were then fixed using $4 \%$ paraformaldehyde for $20 \mathrm{~min}$ at $22^{\circ} \mathrm{C}$. After the fixation, the cells were treated with $1 \%$ crystal violet staining for $15 \mathrm{~min}$ at $22^{\circ} \mathrm{C}$. An optical microscope (Olympus Corporation) at x200 magnification was used to analyze the invasive abilities of the cells.

Cell adhesion assay. The Cell Adhesion Detection kit (BestBio Science) was employed to analyze the adhesion ability of U2OS and Saos-2 cells. Briefly, the coating buffer (100 $\mu \mathrm{l})$ was transferred to each well in a 96-well plate and was left overnight at $4^{\circ} \mathrm{C}$. The following day, the coating buffer was removed, and the plate was cleansed three times with a detergent solution. 
Cells were then digested with trypsin. Following which, they were washed with PBS and resuspended with the RPMI-1640 medium. This procedure was followed by the preparation of the cell suspension. Subsequently, $1 \times 10^{5}$ cells were inoculated into the 96-well plate in each well. Five duplicate wells were established as the experimental group, while five untreated wells served as the control group. The cells were incubated at $37^{\circ} \mathrm{C}$ for $30 \mathrm{~min}$. The culture medium in the control group was not discarded, and the culture medium in the experimental group was replaced by a fresh culture medium. After the cell staining solution B $(100 \mu \mathrm{l})$ was transferred to each well, the cells were incubated for $1 \mathrm{~h}$ at $37^{\circ} \mathrm{C}$. A microplate reader was used to record the optical density value at $450 \mathrm{~nm}$. Finally, the cell adhesion rate was analyzed based on that OD value.

Dual-luciferase reporter assay. All the wild-type (WT) or mutant (MUT) vectors were purchased from Shanghai GenePharma Co., Ltd. Briefly, circ_0032463 segment with either WT or MUT biding sites was transformed and subcloned into the psiCHECK-2 vector (Promega Corporation). The OS

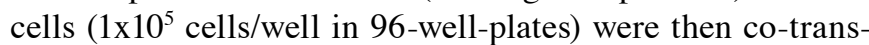
fected with MUT or WT circ_0032463 and the miR-330-3p mimic or mimic NC. After a transfection period of $48 \mathrm{~h}$, the Dual-Luciferase Reporter kit (Promega Corporation) was employed to measure the luciferase activity. Similarly, the MUT or WT 3'-UTR fragment of PNN with or without the predicted miR-330-3p binding sites was amplified using QuikChange Site-Directed Mutagenesis kit (Agilent Technologies, Inc.), according to the manufacturer's protocol, and subcloned into the pmirGLO vector (Promega Corporation). This step was followed by co-transfection with miR-330-3p mimic or mimic $\mathrm{NC}$ to identify luciferase activities. The relative luciferase activity was normalized by Renilla luciferase activity.

RNA Immunoprecipitation Chip (RIP) assay. This assay was performed with the Magna RIP ${ }^{\text {тм }}$ RNA-Binding Protein Immunoprecipitation kit (EMD Millipore), according to the manufacturer's protocols. $1 \times 10^{7}$ cells were then treated with RIP lysis buffer (100 $\mu \mathrm{l})$ containing RNase inhibitors and protease inhibitor cocktail. The cell lysates $(200 \mu \mathrm{l})$ were then incubated with $5 \mu \mathrm{g}$ magnetic beads conjugated to anti-Ago2 (cat. no. 03-110; EMD Millipore) or anti-IgG (negative control; cat. no. 03-110; EMD Millipore) after rinsing with washing buffer, and rotated overnight at $4^{\circ} \mathrm{C}$. After treatment with proteinase $\mathrm{K}$, the immunoprecipitated RNAs were extracted by $500 \mu \mathrm{TRIzol}^{\circledR}$ reagent (Invitrogen; Thermo Fisher Scientific, Inc.), and centrifuged at $4^{\circ} \mathrm{C}$ and $10,000 \mathrm{x}$ g for $10 \mathrm{~min}$. Finally, RT-qPCR was performed to measure circ_0032463 and miR-330-3p enrichment.

RNA pull-down. The OS cells $\left(1 \times 10^{7}\right)$ were treated with $500 \mu 1$ cell lysis buffer containing $2.5 \mathrm{mM}$ EDTA, $25 \mathrm{mM}$ Tris- $\mathrm{HCl}$, $70 \mathrm{mM} \mathrm{KCl}, 0.05 \% \mathrm{NP}-40$, RNase inhibitors and protease inhibitor cocktail. After centrifugation at $4^{\circ} \mathrm{C}$ and $10,000 \mathrm{x} \mathrm{g}$ for $15 \mathrm{~min}$, the OS cell lysates in the supernatant were collected. Next, biotinylated RNA probes (Bio-miR-330-3p and Bio-NC), along with Streptavidin magnetic beads (Thermo Fisher Scientific, Inc.), were incubated overnight at $4^{\circ} \mathrm{C}$ with the OS cell lysates. This was performed based on the manufacturer's protocols of the Pierce ${ }^{\mathrm{TM}}$ Magnetic RNA Pull-Down kit (Pierce; Thermo Fisher Scientific, Inc.). Subsequently, the RNA attached to the beads was separated with washing buffer twice, and the bio-miRNA/mRNA complex was collected with centrifugation at 5,000 x g for $30 \mathrm{sec}$ to identify PNN mRNA enrichment using RT-qPCR. The biotinylated RNA probes used above were designed and synthesized by Guangzhou RiboBio Co., Ltd.

Western blotting. Protein samples were extracted from the cells using RIPA lysis buffer (Beyotime Institute of Biotechnology), and the protein concentration was measured with a BCA Protein Assay kit (Bio-Rad Laboratories, Inc.). Protein samples $(20 \mu \mathrm{g})$ were separated via $10 \%$ SDS-PAGE gel, and subsequently transferred to PVDF membranes (EMD Millipore) and blocked with 5\% non-fat milk for $1 \mathrm{~h}$ at room temperature. After blocking, 5\% non-fat milk was removed, and the membranes were incubated with primary antibodies, including anti-PNN (1:1,000; cat. no. ab244250; Abcam) and anti-GAPDH (1:1,000; cat. no. ab9485; Abcam), overnight at $4^{\circ} \mathrm{C}$. The following day, the secondary antibody $(1: 5,000$; cat. no. ab6728; Abcam) was incubated with the membranes at $20-22^{\circ} \mathrm{C}$ for $1 \mathrm{~h}$. The protein band was visualized with a chemiluminescent substrate (Thermo Fisher Scientific, Inc.), and analyzed using ImageJ version 1.46 (National Institutes of Health).

Data analysis. SPSS 22.0 software (IBM Corp.) was employed for statistical analyses. Three independent experiments were performed, and the data are presented as the mean \pm standard deviation. While the Student's t-test was used to compare two groups, one-way ANOVA with Dunnett's or Tukey's post hoc tests was utilized to compare multiple groups. Pearson's correlation analysis was performed to determine the correlations between miR-330-3p expression and circ_0032463 or PNN expression. $\mathrm{P}<0.05$ was considered to indicate a statistically significant difference.

\section{Results}

Identification of circ_0032463/miR-330-3p/PNN axis in OS. To screen for the key circRNA, the circRNA expression profile GSE96964 was downloaded from GEO database. With $\mathrm{P}<0.05$ and $\log \mathrm{FC}>1$, seven circRNAs were found to be upregulated in OS, including hsa_circ_0032463, hsa_circ_0097271, hsa_circ_0113706, hsa_circ_01113888, hsa_circ_0012726, hsa_circ_01368332 and hsa_circ_0113185 (Table III). Then, RT-qPCR analyses were performed to validate circRNA expression in the 13 tumor tissues and corresponding normal tissues obtained from participants. The results showed that hsa_circ_0032463 had the highest expression in the OS tumor tissues compared with the normal tissue (Fig. 1A-G). Thus, hsa_circ_0032463 was chosen as the circRNA of interest. The structure of circ_0032463 is shown in Fig. 1H. To identify the key gene, two mRNA expression profiles (GSE16088 and GSE12865) were downloaded from the GEO database. With $\mathrm{P}<0.05$ and $\log \mathrm{FC}>1,162$ upregulated genes were screened out (Fig. 1I). After uploading 162 genes to STRING, secreted phosphoprotein, PNN and collagen $\alpha-1(\mathrm{XV})$ chain were confirmed to be associated with cell adhesion (Fig. 1J). Due to the limited studies on PNN in OS, PNN was identified 
Table III. Seven upregulated circRNAs screened from GSE96964 dataset with $\mathrm{P}<0.05$ and $\log \mathrm{FC}>1$.

\begin{tabular}{lcl}
\hline circHome & P-value & LogFC \\
\hline circ_0032463 & 0.01898124 & 1.6991703 \\
circ_0097271 & 0.00988923 & 1.548159 \\
circ_0113706 & 0.03454026 & 1.3707054 \\
circ0111388 & 0.03330578 & 1.2384044 \\
circ_0012726 & 0.03208378 & 1.2261671 \\
circ0136823 & 0.02128171 & 1.1761047 \\
circ_0113185 & 0.04863966 & 1.1112614 \\
\hline
\end{tabular}

FC, fold-change; circ/circRNA, circular RNA.

as the gene of interest. CircInteractome was later utilized to predict the miRNAs sponged by circ_0032463, while starBase and TargetScan were used to predict the miRNAs that target PNN. Finally, has-miR-330-3p and has-miR-543 were found to be overlapped in each of the database searches (Fig. 1K). As miR-330-3p has been identified as a tumor suppressor in OS (33), and has potential roles in the prognosis of OS (25), miR-330-3p was chosen as the miRNA of interest.

Circ_0032463 is upregulated in OS. The expression of circ_0032463 in the human fetal osteoblast cell line (hFOB1.19) and OS cell lines (U2OS, HOS, Saos-2 and SOSP-9607) was measured using RT-qPCR. The enrichment of circ_0032463 in OS cells was more pronounced than that of hFOB1.19 cells (Fig. 2A). As the expression of circ_0032463 was higher in Saos-2 and U2OS cells than that in other OS cells, U2OS and Saos-2 were used in subsequent experiments. As illustrated in Fig. 2B, the level of the linear form of SIPA1L1 declined significantly with the exposure to RNase R treatment. However, circ_0032463 could not be removed with RNase R. After isolating cytoplasmic and nuclear fractions, circ_0032463 was found to be enriched in the cytoplasm (Fig. 2C). Overall, the results indicated that circ_0032463 stability enriched in the cytoplasm was upregulated in OS tissues and cells.

Silencing circ_0032463 suppresses the progression of OS cells. To explore the function of circ_0032463 in OS cells, sh-circ_0032463 \#1, sh-circ_0032463 \#2 and sh-circ_0032463 \#3 were synthesized and transfected into U2OS and Saos-2 cell lines. The transfection efficiency is shown in Fig. 3A, the suppressive effect of sh-circ_0032463 \#1 and sh-circ_0032463 \#2 on circ_0032463 expression was most significant. Hence, they were used in subsequent experiments. BrdU assay was performed to detect the proliferative ability of OS cells transfected with sh-circ_0032463 \#1 and sh-circ_0032463 \#2. As depicted in Fig. 3B, circ_0032463 knockdown inhibited cell proliferation by $50 \%$. Similar to the outcome of the BrdU assay, the results of the CCK- 8 assay showed that silencing circ_0032463 suppressed cell viability (Fig. 3C). According to the flow cytometry results, circ_0032463 knockdown could promote the apoptosis rate of OS cells (Fig. 3D). The Transwell assay outcomes indicated that silencing circ_0032463 reduced the number of invaded cells (Fig. 3E). Besides, silencing circ_0032463 also reduced cell adhesion by $40 \%$ compared with the NC group (Fig. 3F). Overall, these results confirmed that silencing circ_0032463 could inhibit the development of OS.

Circ_0032463 is the upstream target of miR-330-3p. Since miR-330-3p was predicted to be the downstream target of circ_0032463 by bioinformatics analysis, miR-330-3p expression in OS was first detected. The results showed that miR-330-3p expression was lower in OS tissues (Fig. 4A). The result also showed that miR-330-3p expression was negatively correlated with circ_0032463 expression using Pearson's correlation analysis (Fig. 4B). It was discovered that miR-330-3p expression in OS cells decreased compared with hFOB1.19 cells (Fig. 4C). CircInteractome was later employed to predict the two biding sites between circ_0032463 and miR-330-3p (Fig. 4D). To examine the relationship between miR-330-3p and circ_0032463, miR-330-3p mimic was constructed and transfected into U2OS and Saos-2 cells (Fig. 4E). After performing the dual-luciferase reporter assay, it was found that the luciferase activity was repressed by $\sim 70 \%$ with the combination of circ_0032463 WT and miR-330-3p mimic, whereas the luciferase activity in the co-MUT circ_0032463 and miR-330-3p mimic group remained unchanged compared with the co-MUT circ_0032463 and NC group (Fig. 4F). Regardless of whether the binding site (MUT1) or another binding site (MUT2) was mutated, the luciferase activity decreased slightly (Fig. 4F). The RIP assay data also indicated that miR-330-3p could bind to circ_0032463 (Fig. 4G). Taken together, the results confirmed that circ_0032463 could sponge miR-330-3p.

Oncogenic effects of circ_0032463 in OS cells are relieved by $m i R-330-3 p$. To ascertain the interaction between miR-330-3p and circ_0032463 in OS cells, circ_0032463 shRNA and/or miR-330-3p inhibitor was introduced into the OS cells. As indicated in Fig. 5A, sh-circ_0032463 increased miR-330-3p expression by $50 \%$, while the miR-330-3p inhibitor decreased it by $60 \%$. The expression of miR-330-3p in the sh-circ_0032463 plus miR-330-3p inhibitor group remained at the same level compared with the NC group. However, the miR-330-3p inhibitor could not regulate circ_0032463 expression or reverse the reduction of circ_0032463 expression that was induced by sh-circ_0032463 (Fig. 5A). BrdU assay data showed that the miR-330-3p inhibitor promoted cell proliferation, and cell proliferation in the sh-circ_0032463 plus miR-330-3p inhibitor group was similar to that in the NC group (Fig. 5B). The CCK- 8 assay results demonstrated the miR-330-3p inhibitor promoted the viability of U2OS and Saos-2 cells (Fig. 5C). Nonetheless, the co-transfection of sh-circ_0032463 plus miR-330-3p inhibitor could reverse the promotive effects caused by miR-330-3p inhibitor (Fig. 5C). The flow cytometry results indicated that the miR-330-3p inhibitor repressed cell apoptosis by $\sim 50 \%$; however, these changes could be reversed by co-transfection with sh-circ_0032463 (Fig. 5D). The miR-330-3p inhibitor increased the invasive ability of U2OS and Saos- 2 cells by $30 \%$, but this change could be restored by silencing circ_0032463 (Fig. 5E). In addition, the 
A

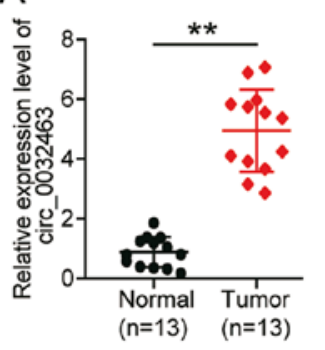

E

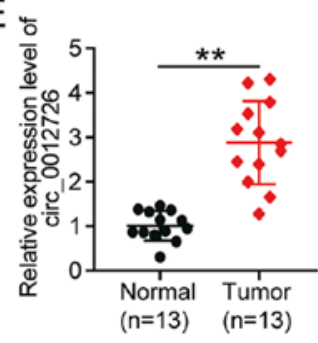

B

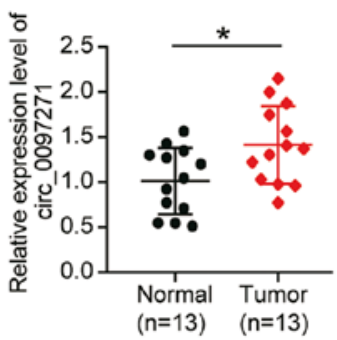

C

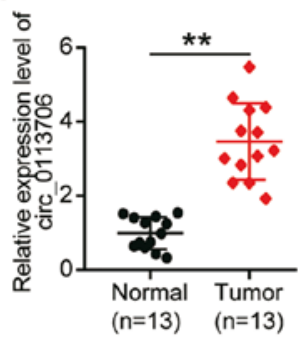

D

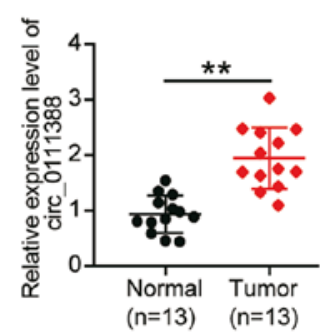

$F_{\text {。 }}$

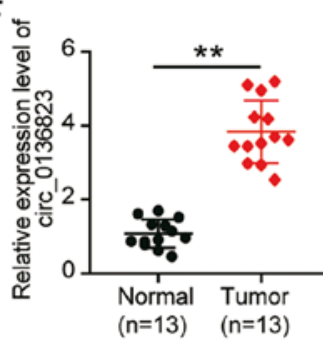

G.

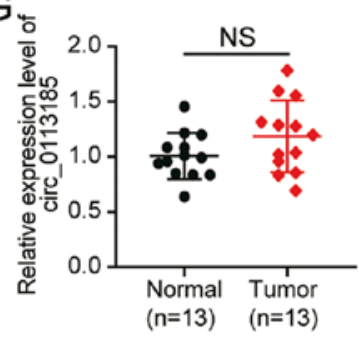

$\mathrm{H}$

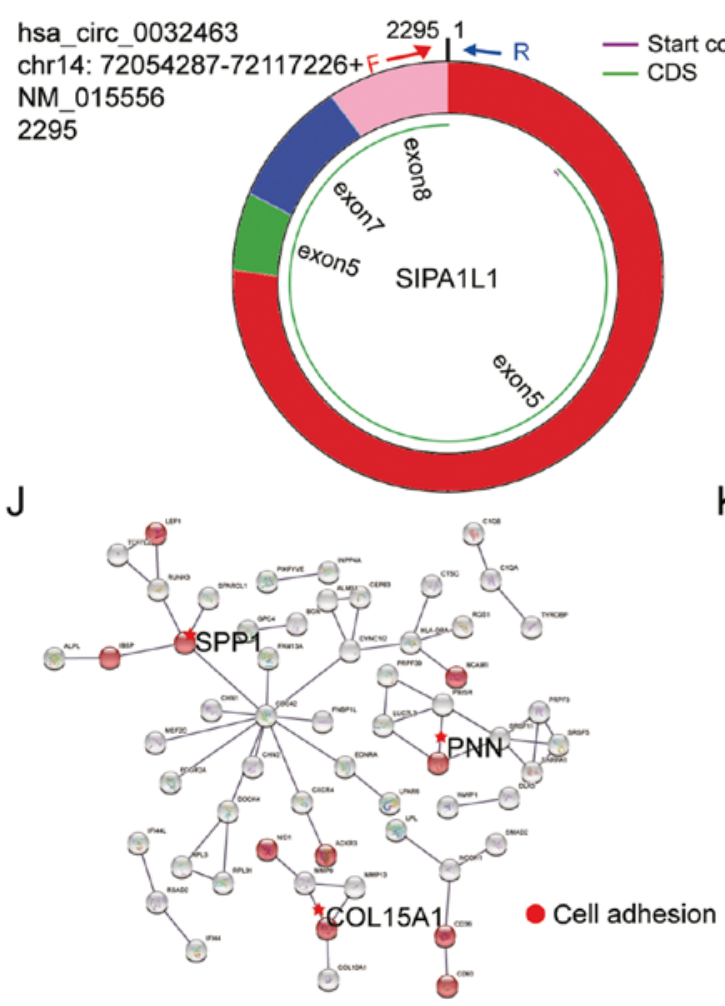

K

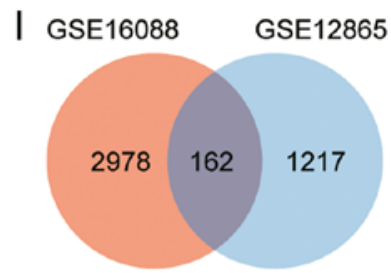

K

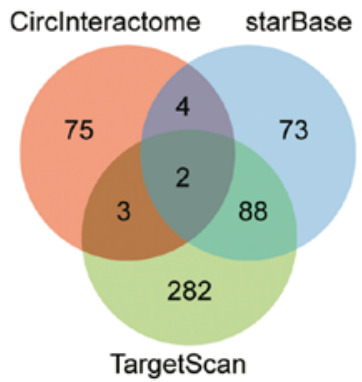

Figure 1. Circ_0032463/miR-330-3p/PNN axis identified as a regulatory pathway in osteosarcoma. (A-G) The relative expression of the seven upregulated circRNAs in 13 tumor tissues and corresponding normal tissues. ${ }^{*} \mathrm{P}<0.05,{ }^{* *} \mathrm{P}<0.001$ vs. normal tissues. Data are presented as the mean \pm SD. (H) The structure of circ_0032463. (I) 162 upregulated genes were overlapped from GSE16088 and GSE12865 with P-value $<0.05$ and $\log$ FC $>1$. (J) SPP1, PNN and COL15A1 were confirmed to be associated with cell adhesion by Search Tool for the Retrieval of Interacting Genes analysis. (K) hsa-miR-330-3p and hsa-miR-543 were overlapped from CircInteractome, starBase and TargetScan databases. circ, circular RNA; miR, microRNA; PNN, Pinin desmosome associated protein; COL15A1, collagen $\alpha-1(\mathrm{XV})$ chain; SPP1, secreted phosphoprotein; NS, no significance.

cell adhesion assay outcomes indicated that circ_0032463 knockdown restricted the promotion of cell adhesion caused by the miR-330-3p inhibitor (Fig. 5F). Overall, these results demonstrated that the oncogenic role of circ_0032463 in OS cells was exerted via miR-330-3p.

miR-330-3p targets PNN in OS cells. PNN was highly expressed more in OS tissues than in normal tissues (Fig. 6A). Besides, PNN expression was negatively correlated to miR-330-3p expression in OS tissues (Fig. 6B). Similarly, PNN
mRNA expression in hFOB1.19 and OS cell lines measured by RT-qPCR indicated that PNN expression in OS cells was higher than that in hFOB1.19 cells (Fig. 6C). The binding sites predicted between miR-330-3p and PNN by TargetScan are illustrated in Fig. 6D. The results of the dual-luciferase reporter assay confirmed that the co-transfection of the miR-330-3p mimic and PNN WT vectors inhibited the luciferase activity; however, no difference was observed in the PNN MUT group in both U2OS and Saos-2 cells (Fig. 6E). This relationship was further determined using the RNA pull-down assay, 


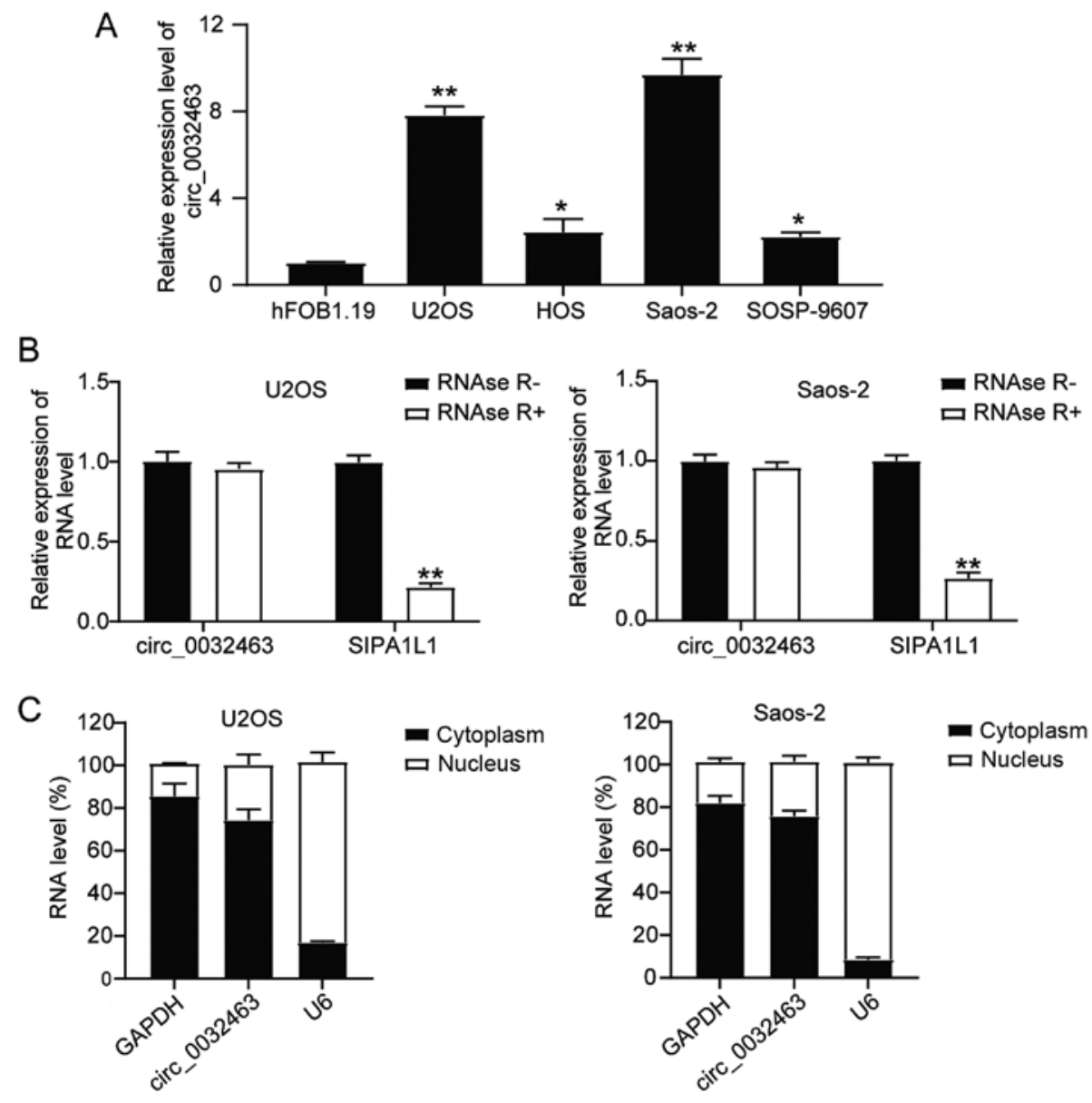

Figure 2. Circ_0032463 may promote OS progression. (A) Circ_0032463 mRNA expression in human fetal osteoblast cell line (hFOB1.19) and OS cell lines (U2OS, HOS, Saos-2 and SOSP-9607), determined by reverse transcription-quantitative PCR. ${ }^{*} \mathrm{P}<0.05,{ }^{* *} \mathrm{P}<0.001$ vs. hFOB1.19 cells. (B) The stability of circ_0032463 in U2OS and Saos-2 cells. *"P $<0.001$ vs. RNAse R' group. (C) The localization of circ_0032463 in cytoplasm and nucleus of U2OS and Saos-2 cells. Data are presented as the mean \pm SD. circ, circular RNA; OS, osteosarcoma; SIPA1L1, signal-induced proliferation-associated 1-like protein 1 .

and experimental analysis showed that PNN could be pulled down by miR-330-3p (Fig. 6F). Moreover, PNN expression was decreased in U2OS and Saos-2 cells transfected with sh-circ_0032463 compared with the sh-NC group, and this could be reversed by the miR-330-3p inhibitor (Fig. 6G). Overall, results indicated that miR-330-3p could target PNN in OS cells.

miR-330-3p inhibits OS cell activities by suppressing PNN. Rescue experiments were carried out to verify whether miR-330-3p could regulate PNN in SaoS2 and U2OS cells. PNN knockdown reduced the mRNA expression of PNN by $70 \%$ compared with the sh-NC group, while the miR-330-3p inhibitor increased it by almost $50 \%$ compared with the NC inhibitor group; nonetheless, the effect could be restored by the co-transfection group (Fig. 7A). Furthermore, sh-PNN did not affect the expression of miR-330-3p or reverse its downregulation induced by miR-330-3p inhibitor. Besides, the protein levels of PNN were similar to the mRNA levels (Fig. 7B). The BrdU assay investigations revealed that silencing PNN decreased cell proliferation by $50 \%$ compared with the NC group; however, this change could be restored by co-transfecting the miR-330-3p inhibitor with sh-PNN (Fig. 7C). Similarly, the CCK-8 assay findings revealed that silencing PNN inhibited cell viability; however, this effect could be abrogated by co-transfecting the miR-330-3p inhibitor with sh-PNN (Fig. 7D). The flow cytometry data showed that sh-PNN could increase the apoptosis of OS cells compared with the NC group; nonetheless, this facilitation could be reversed by co-transfection with the miR-330-3p inhibitor (Fig. 7E). Furthermore, $>40 \%$ reduction of cell invasion and $40 \%$ reduction of cell adhesion induced by silencing PNN could be abolished by co-transfecting the miR-330-3p inhibitor with sh-PNN (Fig. 7F and G). Overall, these outcomes indicated that miR-330-3p could inhibit the activity of OS cells by suppressing PNN.

\section{Discussion}

Adolescents are the most vulnerable groups to OS (34). CircRNAs have been reported to be aberrantly expressed in OS and have various roles in either promoting (35-37) or inhibiting $(12,38)$ the progression of OS tumorigenesis. The present study discovered a novel circRNA (circ_0032463) that was upregulated in OS, indicating its potential role in promoting OS progression. After performing cytological experiments, circ_0032463 was observed to exert positive effects on cell proliferation, viability, invasion and adhesion. However, it inhibited cell apoptosis by acting as a sponge for miR-330-3p, thereby upregulating PNN in Saos-2 and U2OS cells. 

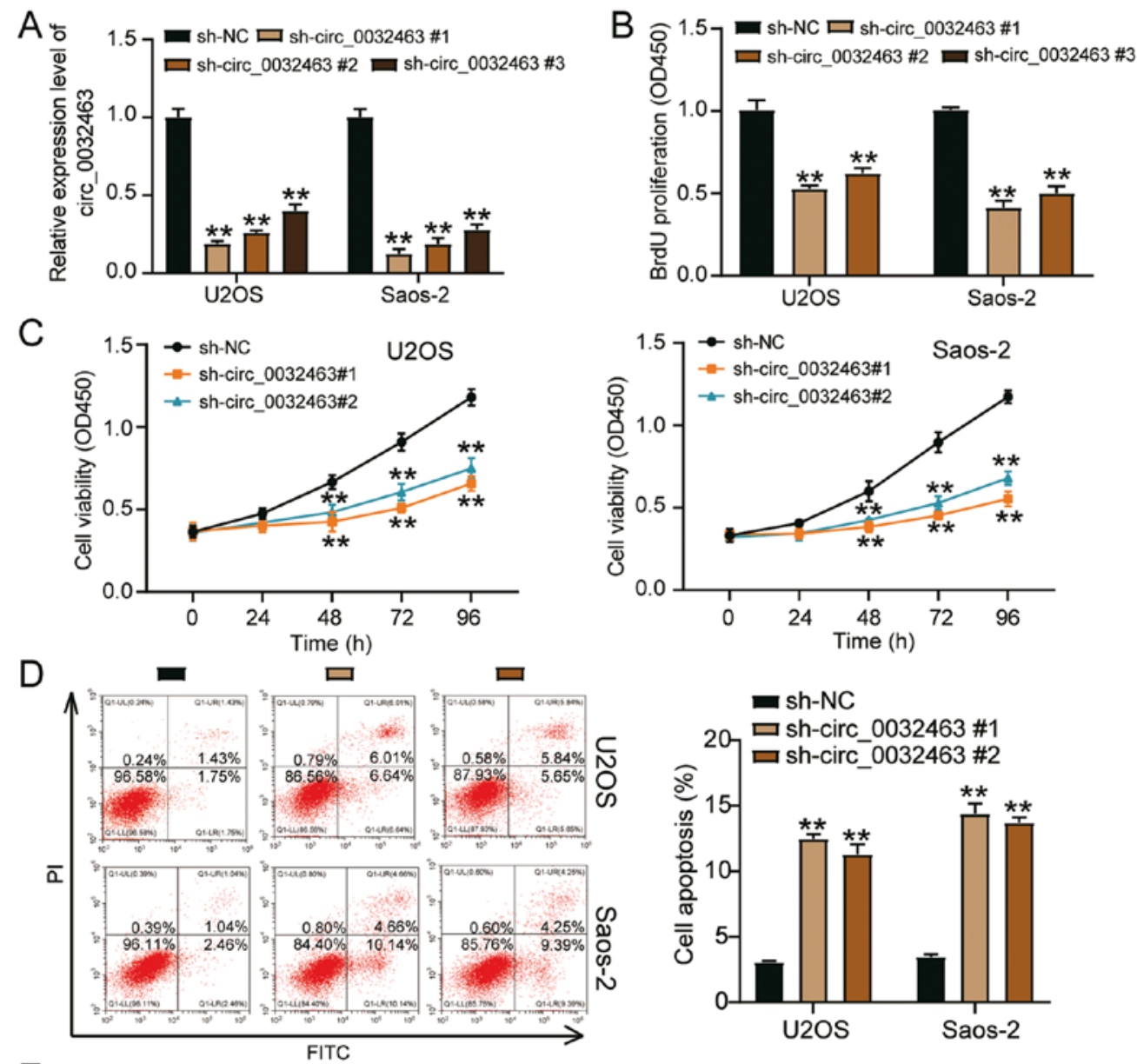

E
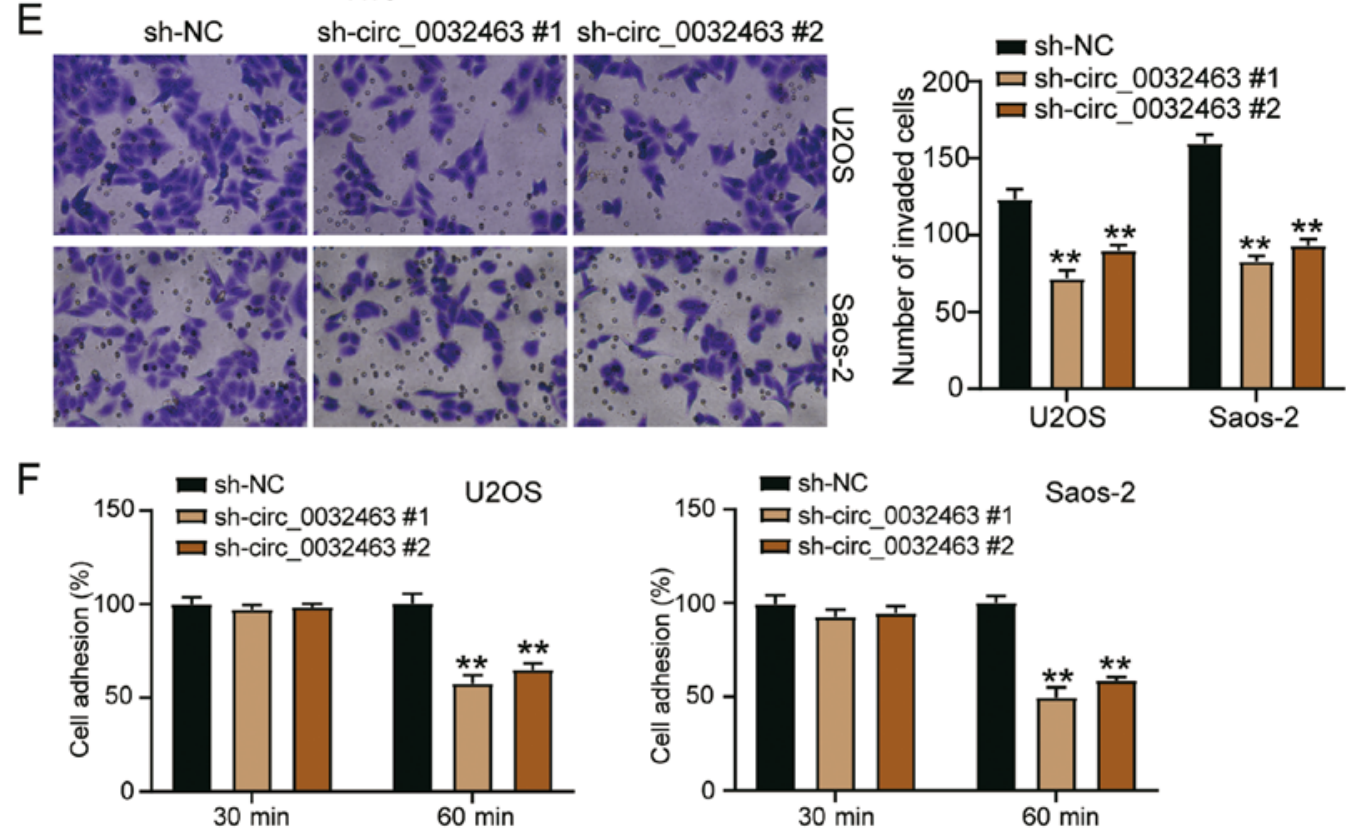

Figure 3. Silencing circ_0032463 expression exerts tumor-suppressive effects on osteosarcoma cells. (A) Transfection efficiency of sh-circ_0032463 \#1, sh-circ_0032463 \#2 and sh-circ_0032463 \#3 in U2OS and Saos-2 cells, determined by reverse transcription-quantitative PCR. (B) Cell proliferation was detected by BrdU assay. (C) Cell viability was detected by a Cell Counting Kit-8 assay. (D) Cell apoptosis was detected by flow cytometry for apoptosis detection. (E) Cell invasion was detected by a Transwell assay. (F) Cell adhesion was detected by a cell adhesion assay. Data are presented as the mean \pm SD. ${ }^{* *} \mathrm{P}<0.001$ vs. sh-NC. circ, circular RNA; sh-, short hairpin RNA; NC, negative control.

Previous research has indicated the significant role of circRNAs in various cancer types $(39,40)$. The present study focused on the role of circRNAs in OS and examined the regulatory mechanism underlying the development of OS from an epigenetic perspective. Evidence in the literature has suggested that circRNAs can play crucial roles in OS development $(35,41,42)$. However, to the best of our knowledge, the present study is the first to demonstrate the role 

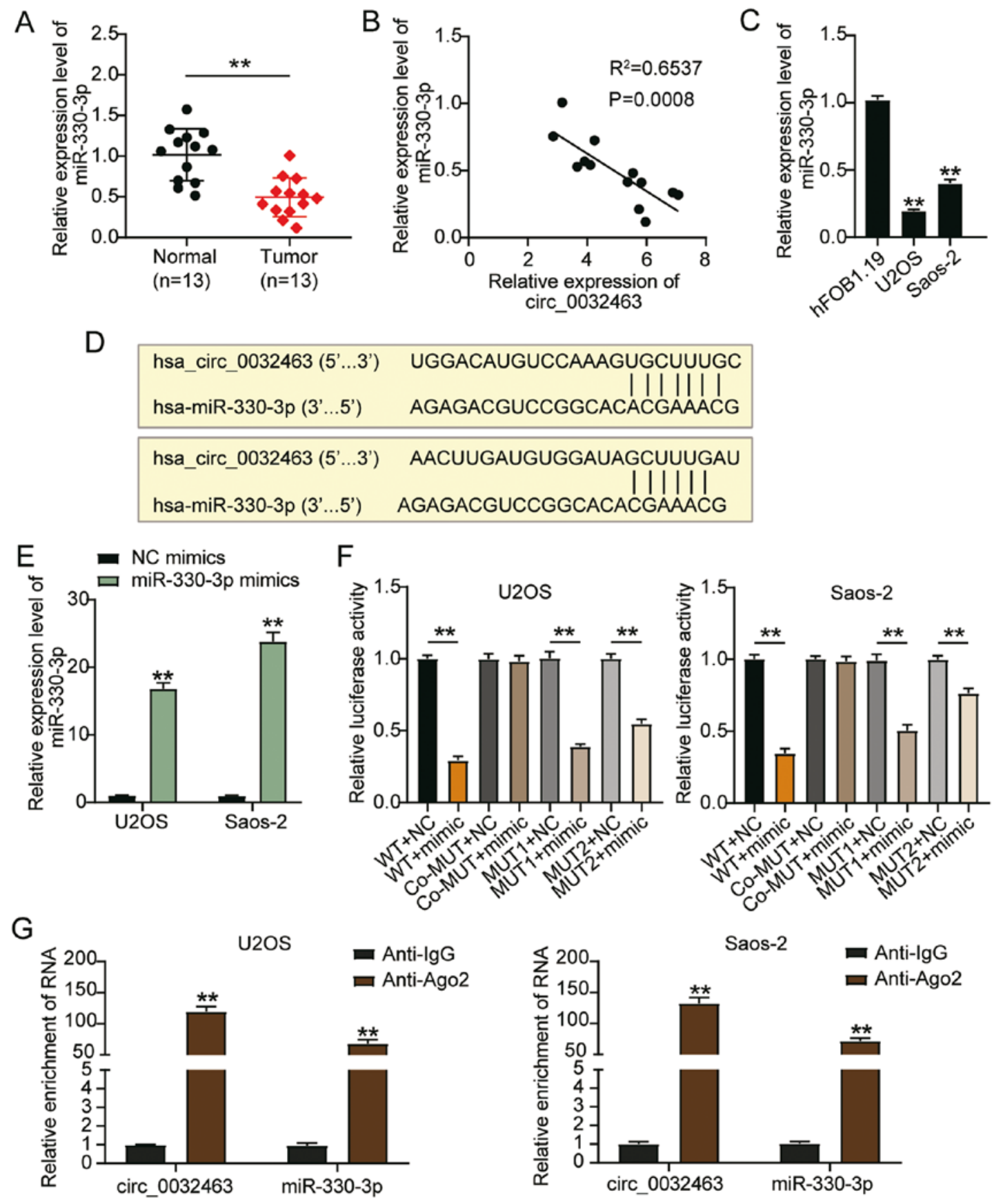

Figure 4. Circ_0032463 may be a sponge for miR-330-3p in OS progression. (A) miR-330-3p expression in OS tissues and normal tissues, determined by RT-qPCR. ${ }^{* *} \mathrm{P}<0.001$ vs. normal tissues. (B) The expression of miR-330-3p had a negative correlation with circ_0032463 expression in U2OS and Saos-2 cells. (C) miR-330-3p expression in human fetal osteoblast cell line (hFOB1.19) and OS cell lines (U2OS and Saos-2), determined by RT-qPCR. ${ }^{* *} \mathrm{P}<0.001$ vs. hFOB1.19 cells. (D) The predicted binding sites between miR-330-3p and circ_0032463. (E) Transfection efficiency of miR-330-3p mimic determined by RT-qPCR in U2OS and Saos-2 cells. ${ }^{* *} \mathrm{P}<0.001$ vs. NC mimics. (F) The target relationship between miR-330-3p and circ_0032463 was verified by dual-luciferase reporter assay. ${ }^{* * *} \mathrm{P}<0.001$ vs. NC. (G) Relative enrichment of circ_0032463 in anti-IgG and anti-Ago2 was detected by RIP assay. Data are presented as the mean $\pm \mathrm{SD} .{ }^{* *} \mathrm{P}<0.001$ vs. anti-IgG group. circ, circular RNA; miR, microRNA; OS, osteosarcoma; NC, negative control; RT-qPCR, reverse transcription-quantitative PCR; RIP, RNA Immunoprecipitation Chip; WT, wild-type; MUT, mutant.

of circ_0032463 in OS cells. After bioinformatics analysis in the present study, it was found that circ_0032463 was upregulated in OS samples, suggesting that circ_0032463 had a promotive effect in OS. Further experimental investigations showed that while the knockdown of circ_0032463 could repress cell proliferation, viability, invasion and adhesion, it could induce cell apoptosis of OS cells. This result suggested that silencing circ_0032463 could suppress OS progression.
Furthermore, circRNAs are often investigated as the key member of competing endogenous (ce)RNA networks, known as the 'circRNA-miRNA-mRNA axis' (12). The 'circRNA-miRNA-mRNA axis' theory speculates that circRNAs mainly sponge miRNAs to regulate the downstream target genes of miRNAs (43). With this in mind, the present study examined how circ_0032463 could influence the development of OS through a miRNA-mediated mechanism. After performing bioinformatics analysis and cytological experi- 

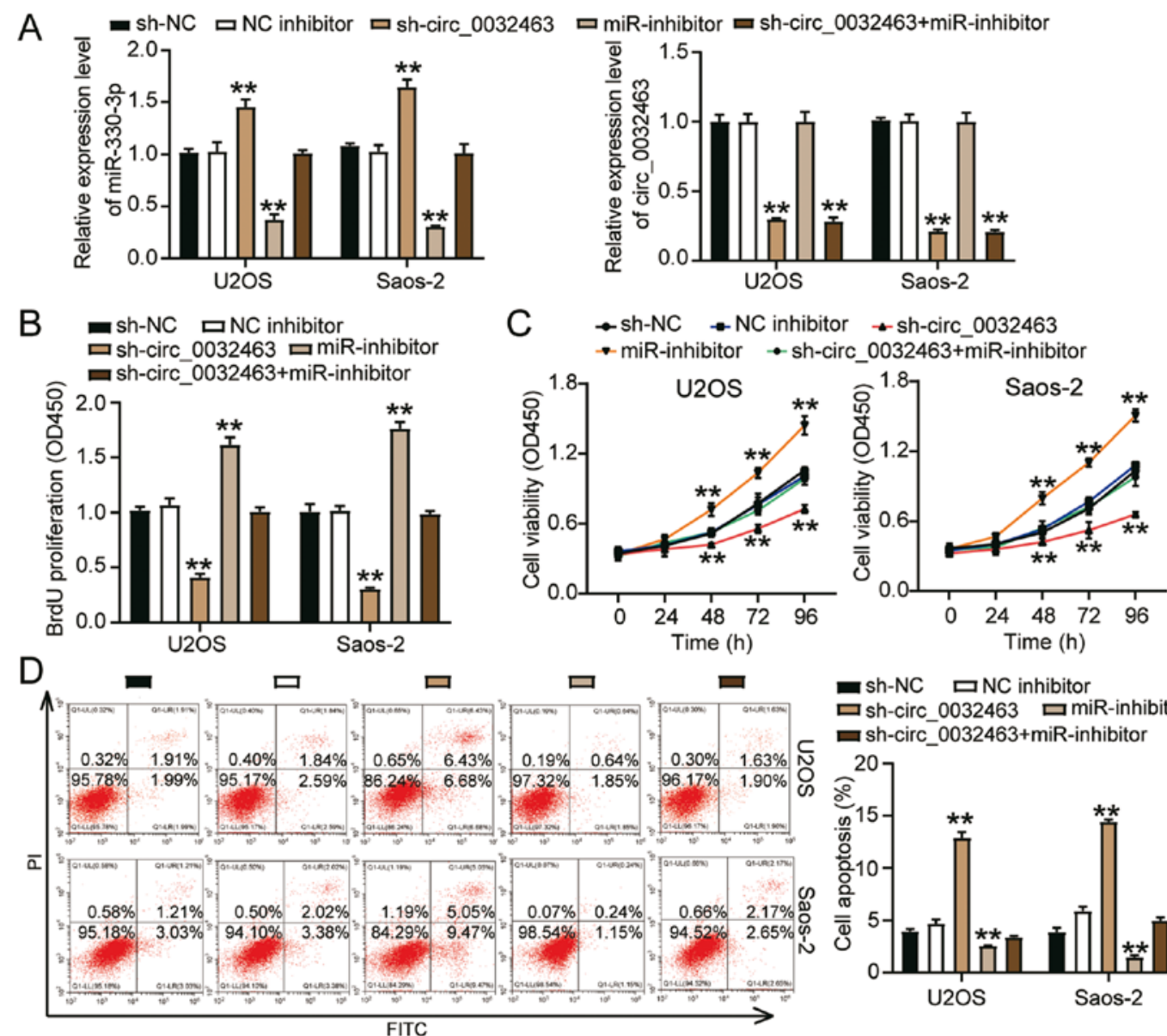

口sh-NC 口NC inhibitor
口sh-circ_0032463 口miR-inhibitor

口sh-circ_0032463 口 घ miR-inhibito

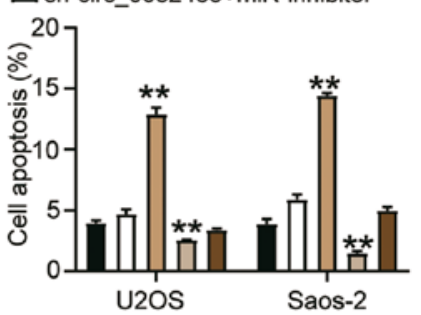

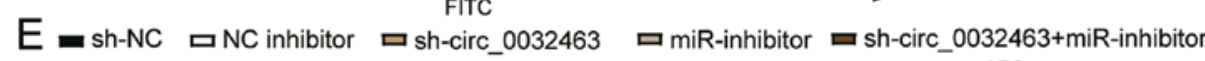
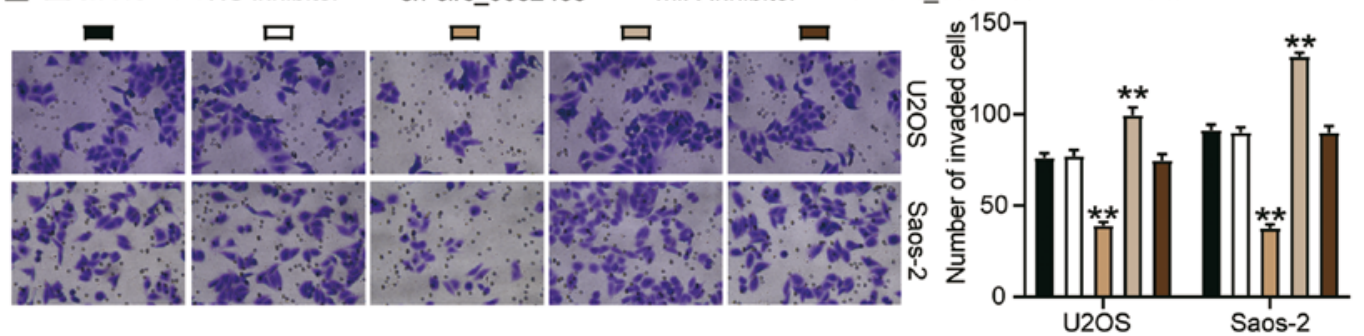

$\mathrm{F}$
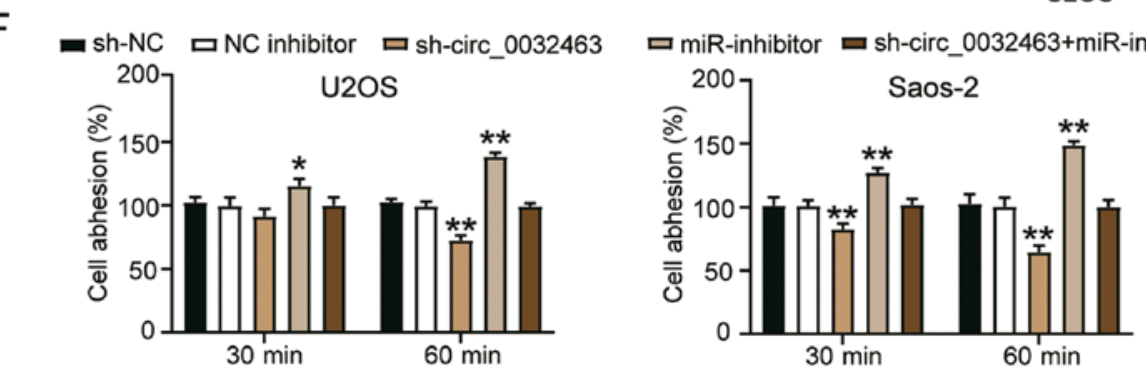

Figure 5. Oncogenic effect of circ_0032463 on osteosarcoma cells is exerted via inhibiting miR-330-3p. U2OS and Saos-2 cells were transfected with sh-circ_0032463, miR-330-3p inhibitor, sh-circ_0032463 + miR-330-3p inhibitor or their corresponding NC. (A) Relative expression of miR-330-3p or circ_0032463 in U2OS and Saos-2 cells, determined by reverse transcription-quantitative PCR. (B) Cell proliferation was detected by a BrdU assay. (C) Cell viability was detected by a Cell Counting Kit-8 assay. (D) Cell apoptosis was detected by flow cytometry for apoptosis detection. (E) Cell invasion was detected by a Transwell assay. (F) Cell adhesion was detected by a cell adhesion assay. Data are presented as the mean $\pm \mathrm{SD}$. ${ }^{*} \mathrm{P}<0.05,{ }^{* *} \mathrm{P}<0.001$ vs. sh-NC. circ, circular RNA; miR, microRNA; sh-, short hairpin RNA; NC, negative control.

ments, it was found that miR-330-3p was the downstream miRNA sponged by circ_0032463 in OS cells. Several studies have documented the suppressive abilities of miR-330-3p in several malignancies, including gastric cancer, liver cancer and melanoma $(23,24,44)$. At present, only one previous study has reported on the role of miR-330-3p in OS, which demonstrated that this miRNA was downregulated and played an antitumor role by targeting Bmi-1 (25). The present findings were consistent with the results of this previous study, as we showed that miR-330-3p suppressed OS progression. However, the inhibitory effect of miR-330-3p on OS could be restored by circ_0032463. The present study also revealed 

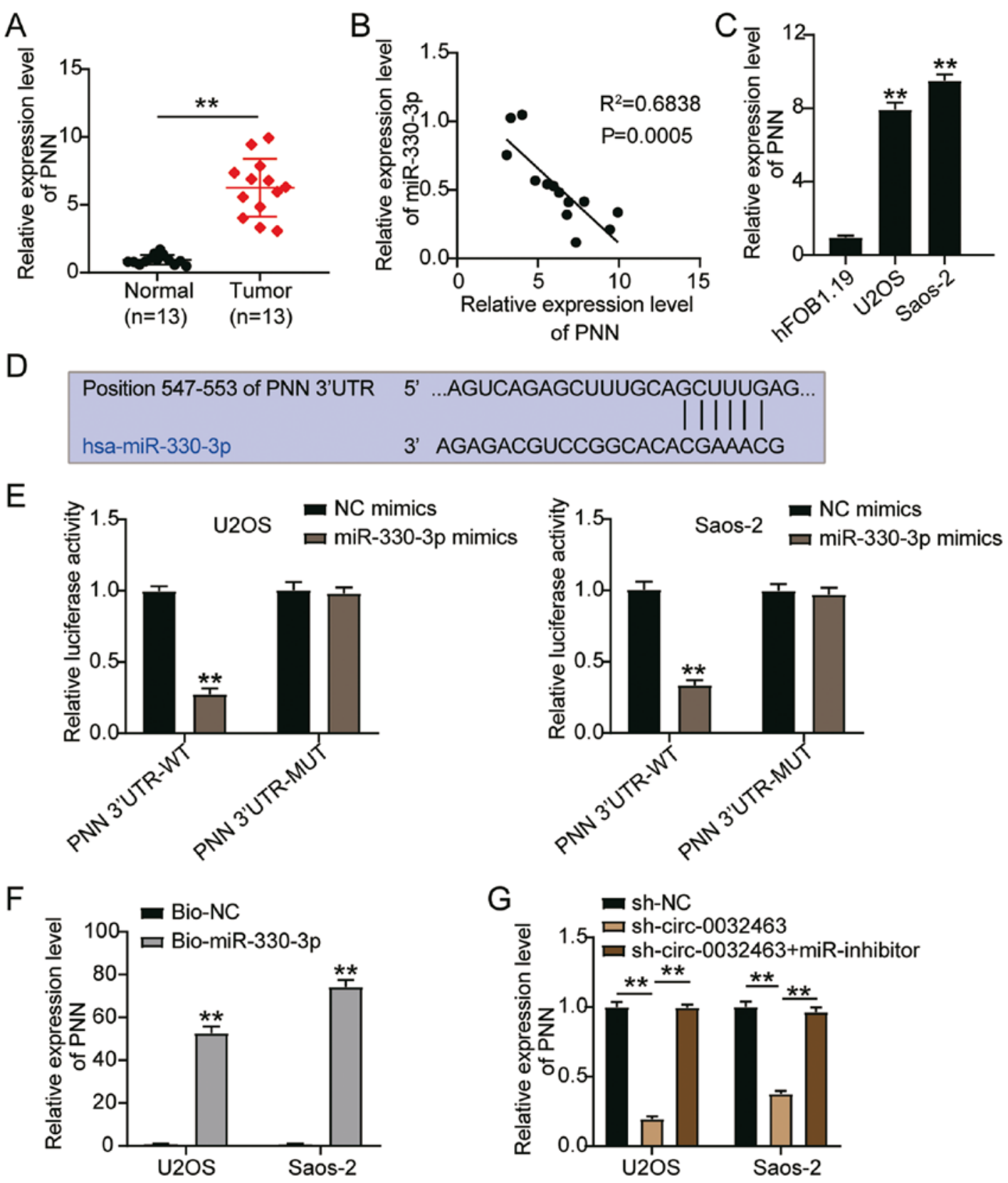

Figure 6. miR-330-3p targets PNN in OS cells. (A) PNN mRNA expression in OS tissues and normal tissues, determined by RT-qPCR. ${ }^{* *}$ P $<0.001$ vs. normal tissues. (B) The correlation analysis between miR-330-3p expression and PNN expression in OS. (C) PNN mRNA expression in human fetal osteoblast cell line (hFOB1.19) and OS cell lines (U2OS and Saos-2), determined by RT-qPCR. ${ }^{* *} \mathrm{P}<0.001$ vs. hFOB1.19 cells. (D) The predicted binding sites between miR-330-3p and PNN. (E) The target relationship between miR-330-3p and PNN was verified by a dual-luciferase reporter assay. ${ }^{* *} \mathrm{P}<0.001$ vs. NC mimics. (F) Relative enrichment of PNN in Bio-miR-330-3p and Bio-NC was detected by a RNA pull-down assay. ${ }^{* *} \mathrm{P}<0.001$ vs. Bio-NC group. (G) Relative expression of PNN in U2OS and Saos-2 cells transfected with sh-NC, sh-circ 0032463 \#1 or sh-circ 0032463 \#1 + miR-330-3p inhibitor. Data are presented as the mean \pm SD. ${ }^{* *} \mathrm{P}<0.001$. circ, circular RNA; miR, microRNA; sh-, short hairpin RNA; NC, negative control; PNN, Pinin desmosome associated protein; OS, osteosarcoma; RT-qPCR, reverse transcription-quantitative PCR; WT, wild-type; MUT, mutant; UTR, untranslated region.

that PNN was the target of miR-330-3p in OS, which was different from the outcomes of previous studies.

PNN, a desmosome-associated molecule, has been demonstrated to be overexpressed and associated with the poor prognosis of numerous types of cancer (27-29). For example, Tang et al (45) revealed that PNN contributed to the epithelial-mesenchymal transition in nasopharyngeal carcinoma by regulating the activity of E-cadherin. The present study speculated that PNN might act as a tumor suppressor in OS based on the information obtained in the literature $(45,46)$. After bioinformatics analyses and in vitro experiments were performed, the present study discovered that PNN was upregulated in OS. It was also found to induce the proliferation, invasion and adhesion of OS cells. Besides, these results indicated that the enhancing effect of PNN in OS could be restored by miR-330-3p.

Although the role of the circ_0032463/miR-330-3p/PNN axis in OS was illustrated, the present study has a few limitations. First, only in vitro experiments were performed. For this reason, in vivo experiments should be conducted in the future to confirm the validity of these results. Moreover, PNN has been found to be associated with cell adhesion (47). Also, a previous study demonstrated that the knockdown of PNN repressed E-cadherin and 

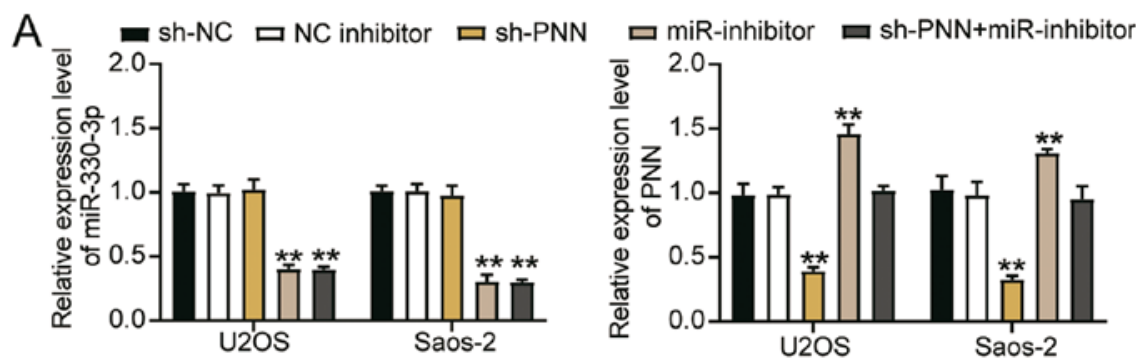

B

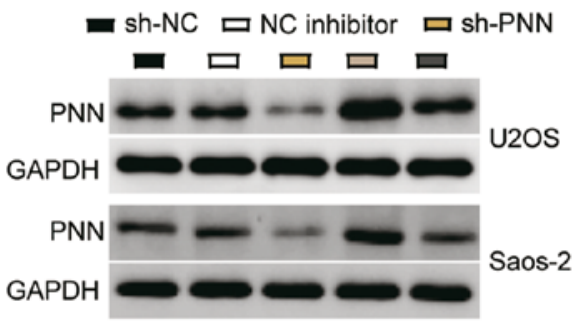

ロ miR-inhibitor घ sh-PNN+miR-inhibitor

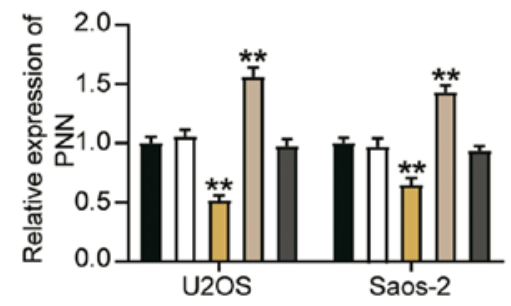

C $=$ sh-NC $\mathrm{NC}$ inhibitor $\square$ sh-PNN

$\mathrm{D} \rightarrow$ sh-NC $\rightarrow$ NC inhibitor $\nrightarrow$ sh-PNN
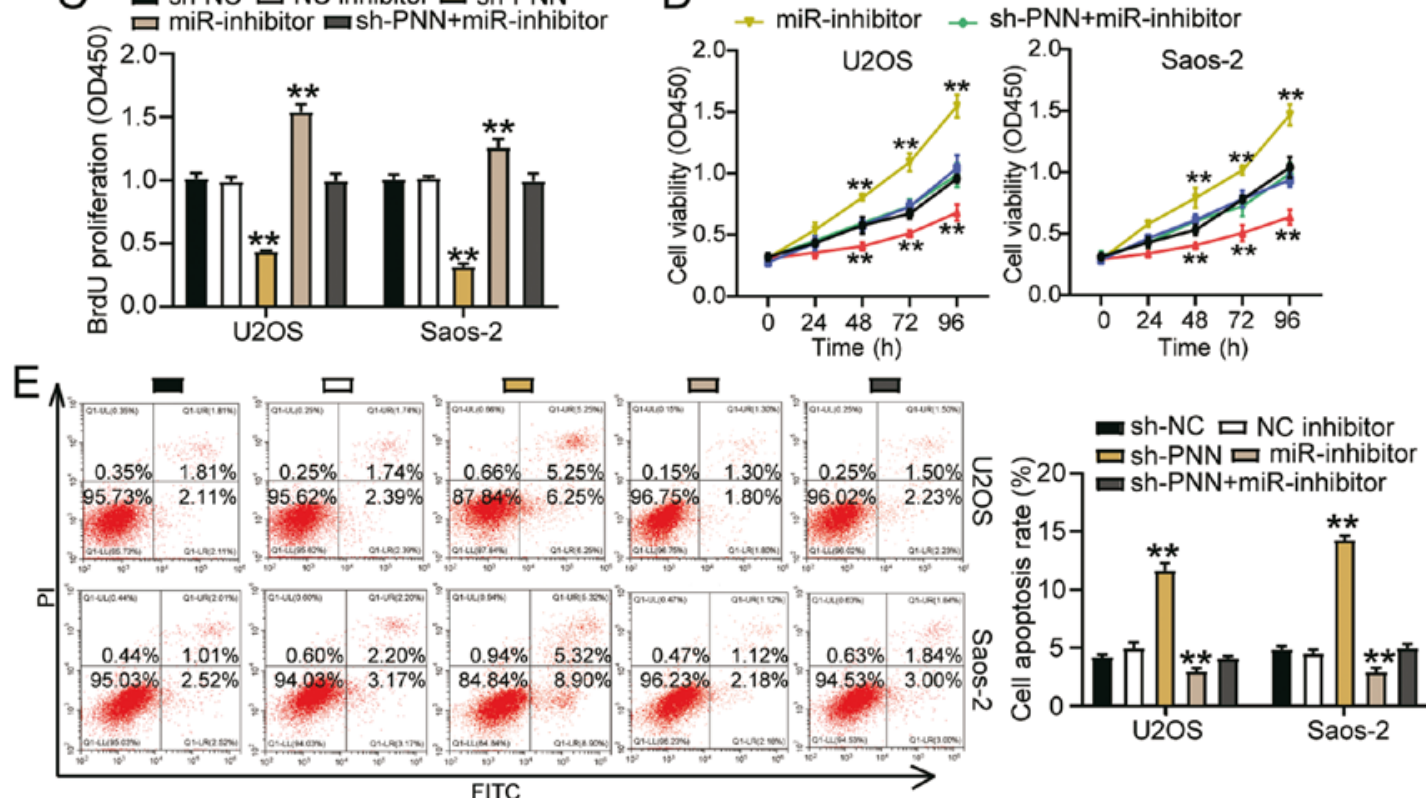

F - sh-NC ロ NC inhibitor ロ
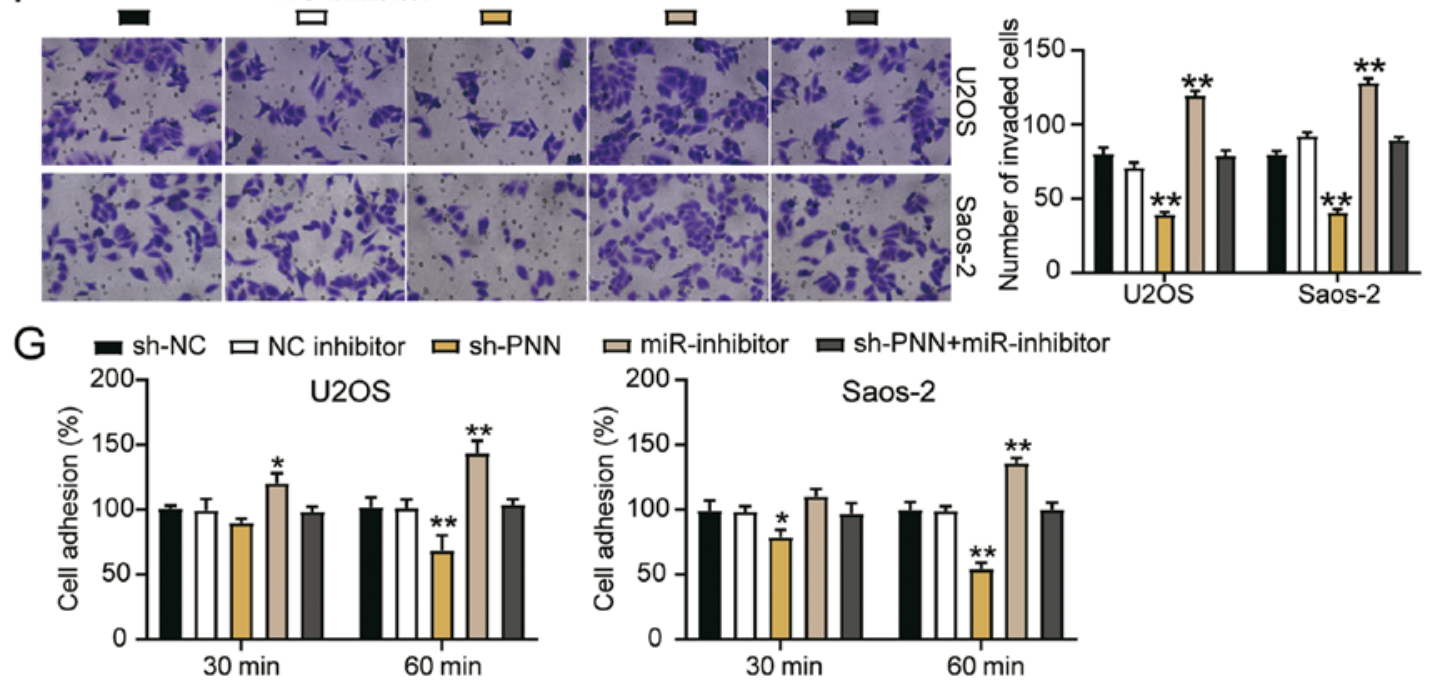

Figure 7. miR-330-3p inhibits osteosarcoma cell activity by suppressing PNN. U2OS and Saos-2 cells were transfected with sh-PNN, miR-330-3p inhibitor, sh-PNN + miR-330-3p inhibitor or their corresponding NC. (A) Expression of miR-330-3p and PNN in U2OS and Saos-2 cells, determined by reverse transcription-quantitative PCR. (B) Protein expression of PNN in U2OS and Saos-2 cells, determined via western blotting. (C) Cell proliferation was detected by a BrdU assay. (D) Cell viability was detected by a Cell Counting Kit-8 assay. (E) Cell apoptosis was detected by flow cytometry for apoptosis detection. (F) Cell invasion was detected by a Transwell assay. (G) Cell adhesion was detected by a cell adhesion assay. Data are presented as the mean \pm SD. "P $<0.05$, ${ }_{* * *} \mathrm{P}<0.001$ vs. NC. miR, microRNA; sh-, short hairpin RNA; NC, negative control; PNN, Pinin desmosome associated protein. 
DSG2, which in turn reduced epithelial adhesion (48). This could indicate that the interaction of PNN with other relevant factors, such as E-cadherin and DSG2, could affect OS cell adhesion. This area of research should be explored in the future.

In conclusion, the present research demonstrated that by sponging miR-330-3p to upregulate PNN, circ_0032463 could act as a tumor promoter in OS cells. This study also confirmed the role of the circ_0032463/miR-330-3p/PNN axis in OS development. This knowledge could be useful in the diagnosis, prognosis and treatment of OS.

\section{Acknowledgements}

Not applicable.

\section{Funding}

No funding was received.

\section{Availability of data and materials}

The datasets used and/or analyzed during the current study are available from the corresponding author on reasonable request.

\section{Authors' contributions}

GQ performed the experiments and data analysis. XW conceived and designed the study, and wrote the paper. GQ reviewed and edited the manuscript. GQ and XW confirm the authenticity of all the raw data. All authors read and approved the final manuscript.

\section{Ethics approval and consent to participate}

The present study was approved by the Ethics Committee of The First Affiliated Hospital of Zhengzhou University (Zhengzhou, China). Informed consent was obtained from the patients before they could participate in the experiment.

\section{Patient consent for publication}

Not applicable.

\section{Competing interests}

The authors declare that they have no competing interests.

\section{References}

1. Rickel K, Fang F and Tao J: Molecular genetics of osteosarcoma. Bone 102: 69-79, 2017.

2. Savage SA and Mirabello L: Using epidemiology and genomics to understand osteosarcoma etiology. Sarcoma 2011: 548151, 2011.

3. Isakoff MS, Bielack SS, Meltzer P and Gorlick R: Osteosarcoma: Current treatment and a collaborative pathway to success. J Clin Oncol 33: 3029-3035, 2015.

4. Otoukesh B, Boddouhi B, Moghtadaei M, Kaghazian P and Kaghazian M: Novel molecular insights and new therapeutic strategies in osteosarcoma. Cancer Cell Int 18: 158, 2018.

5. Bishop MW, Janeway KA and Gorlick R: Future directions in the treatment of osteosarcoma. Curr Opin Pediatr 28: 26-33, 2016.

6. Kristensen LS, Andersen MS, Stagsted LVW, Ebbesen KK, Hansen TB and Kjems J: The biogenesis, biology and characterization of circular RNAs. Nature Rev Genet 20: 675-691, 2019.
7. Hansen TB, Jensen TI, Clausen BH, Bramsen JB, Finsen B, Damgaard CK and Kjems J: Natural RNA circles function as efficient microRNA sponges. Nature 495: 384-388, 2013.

8. Kristensen LS, Hansen TB, Venø MT and Kjems J: Circular RNAs in cancer: opportunities and challenges in the field. Oncogene 37: 555-565, 2018.

9. Wang C, Ren M, Zhao X, Wang A and Wang J: Emerging roles of circular RNAs in osteosarcoma. Med Sci Monit 24: 7043-7050, 2018.

10. Zhang Y, Li J, Wang Y, Jing J and Li J: The roles of circular RNAs in osteosarcoma. Med Sci Monit 25: 6378-6382, 2019.

11. Li H, Lan M, Liao X, Tang Z and Yang C: Circular RNA cir-ITCH promotes osteosarcoma migration and invasion through cir-ITCH/miR-7/EGFR pathway. Technol Cancer Res Treat: Jan 21, 2020 (Epub ahead of print). doi: 10.1177/1533033819898728.

12. Chen L, Shan Y, Zhang H, Wang H and Chen Y: Up-regulation of Hsa_circ 0008792 inhibits osteosarcoma cell invasion and migration and promotes apoptosis by regulating Hsa-miR-711/ZFP1. OncoTargets Ther 13: 2173-2181, 2020.

13. Bartel DP: MicroRNAs: Target recognition and regulatory functions. Cell 136: 215-233, 2009.

14. Liang M, Huang G, Liu Z, Wang Q, Yu Z, Liu Z, Lin H, Li M, Zhou X and Zheng Y: Elevated levels of hsa_circ_006100 in gastric cancer promote cell growth and metastasis via miR-195/GPRC5A signalling. Cell Prolif 52: e12661, 2019.

15. Rong X, Gao W, Yang X and Guo J: Downregulation of hsa_circ_0007534 restricts the proliferation and invasion of cervical cancer through regulating miR-498/BMI-1 signaling. Life Sci 235: 116785, 2019.

16. Yao J, Zhang C, Chen Y and Gao S: Downregulation of circular RNA circ-LDLRAD3 suppresses pancreatic cancer progression through miR-137-3p/PTN axis. Life Sci 239: 116871, 2019.

17. Zhang CL, Li LB, She C, Xie Y, Ge DW and Dong QR: MiR-299-5p targets cell cycle to promote cell proliferation and progression of osteosarcoma. Eur Rev Med Pharmacol Sci 22: 2606-2613, 2018

18. Lv DB, Zhang JY, Gao K, Yu ZH, Sheng WC, Yang G and Gao YZ: MicroRNA-765 targets MTUS1 to promote the progression of osteosarcoma via mediating ERK/EMT pathway. Eur Rev Med Pharmacol Sci 23: 4618-4628, 2019.

19. Loughlin V and Beniwal JS: Post-traumatic brachial artery aneurysm and arteriovenous fistulae. J Cardiovasc Surg (Torino) 29: 570-571, 1988.

20. Liu G, Huang K, Jie Z, Wu Y, Chen J, Chen Z, Fang X and Shen S: CircFAT1 sponges miR-375 to promote the expression of Yes-associated protein 1 in osteosarcoma cells. Mol Cancer 17: $170,2018$.

21. Xu R, Feng F, Yu X, Liu Z and Lao L: LncRNA SNHG4 promotes tumour growth by sponging miR-224-3p and predicts poor survival and recurrence in human osteosarcoma. Cell Proliferation 51: e12515, 2018.

22. He M, Shen P, Qiu C and Wang J: miR-627-3p inhibits osteosarcoma cell proliferation and metastasis by targeting PTN. Aging 11: 5744-5756, 2019.

23. Jin Z, Jia B, Tan L and Liu Y: miR-330-3p suppresses liver cancer cell migration by targeting MAP2K1. Oncol Lett 18: 314-320, 2019.

24. Guan A, Wang H, Li X, Xie H, Wang R, Zhu Y and Li R: MiR-330-3p inhibits gastric cancer progression through targeting MSI1. Am J Transl Res 8: 4802-4811, 2016.

25. Zheng $Z$, Bao $F$, Chen $X$, Huang $H$ and Zhang $X$ : MicroRNA-330-3p expression indicates good prognosis and suppresses cell proliferation by targeting bmi-1 in osteosarcoma. Cell Physiol Biochem 46: 442-450, 2018.

26. Mini E, Lapucci A, Perrone G, D'Aurizio R, Napoli C, Brugia M, Landini I, Tassi R, Picariello L, Simi L et al: RNA sequencing reveals PNN and KCNQ1OT1 as predictive biomarkers of clinical outcome in stage III colorectal cancer patients treated with adjuvant chemotherapy. Int J Cancer 145: 2580-2593, 2019.

27. Zhang Y, Kwok JS, Choi PW, Liu M, Yang J, Singh J, Ng SK, Welch WR, Muto MG, Tsui SK, et al: Pinin interacts with C-terminal binding proteins for RNA alternative splicing and epithelial cell identity of human ovarian cancer cells. Oncotarget 7: 11397-11411, 2016.

28. Wei Z, Ma W, Qi X, Zhu X, Wang Y, Xu Z, Luo J, Wang D, Guo W, Li X, et al: Pinin facilitated proliferation and metastasis of colorectal cancer through activating EGFR/ERK signaling pathway. Oncotarget 7: 29429-29439, 2016. 
29. Yang X, Sun D, Dong C, Tian Y, Gao Z and Wang L: Pinin associates with prognosis of hepatocellular carcinoma through promoting cell proliferation and suppressing glucose deprivation-induced apoptosis. Oncotarget 7: 39694-39704, 2016.

30. Paoloni M, Davis S, Lana S, Withrow S, Sangiorgi L, Picci P, Hewitt S, Triche T, Meltzer P and Khanna C: Canine tumor cross-species genomics uncovers targets linked to osteosarcoma progression. BMC Genomics 10: 625, 2009.

31. Sadikovic B, Yoshimoto M, Chilton-MacNeill S, Thorner P Squire JA and Zielenska M: Identification of interactive networks of gene expression associated with osteosarcoma oncogenesis by integrated molecular profiling. Human Mol Genet 18: 1962-1975, 2009.

32. Livak KJ and Schmittgen TD: Analysis of relative gene expression data using real-time quantitative PCR and the 2(-Delta Delta C(T)) method. Methods 25: 402-408, 2001.

33. Wang H, Liu L and Fang S: MicroRNA-330-5p inhibits osteosarcoma cell growth and invasion by targeting the proto-oncogene survivin. Mol Med Rep 20: 2236-2244, 2019.

34. Caudill JS and Arndt CA: Diagnosis and management of bone malignancy in adolescence. Adolesc Med State Art Rev 18 62-78, ix, 2007.

35. Zhang H, Yan J,Lang X and Zhuang Y: Expression of circ_001569 is upregulated in osteosarcoma and promotes cell proliferation and cisplatin resistance by activating the $\mathrm{Wnt} / \beta$-catenin signaling pathway. Oncol Lett 16: 5856-5862, 2018.

36. Zhang Z, Pu F, Wang B, Wu Q, Liu J and Shao Z: Hsa circ_0000285 functions as a competitive endogenous RNA to promote osteosarcoma progression by sponging hsa-miRNA-599. Gene therapy 27: 186-195, 2020.

37. Liu X, Zhong Y, Li J and Shan A: Circular RNA circ-NT5C2 acts as an oncogene in osteosarcoma proliferation and metastasis through targeting miR-448. Oncotarget 8: 114829-114838, 2017.

38. Wu Z, Shi W and Jiang C: Overexpressing circular RNA hsa circ_0002052 impairs osteosarcoma progression via inhibiting $\mathrm{Wnt} / \beta$-catenin pathway by regulating $\mathrm{miR}-1205 / \mathrm{APC} 2$ axis Biochem Biophys Res Commun 502: 465-471, 2018.

39. Qian L, Yu S, Chen Z, Meng Z, Huang S and Wang P: The emerging role of circRNAs and their clinical significance in human cancers. Biochimica Biophys Acta Rev Cancer 1870: 247-260, 2018

40. Chen BJ, Byrne FL, Takenaka K, Modesitt SC, Olzomer EM, Mills JD, Farrell R, Hoehn KL and Janitz M: Analysis of the circular RNA transcriptome in endometrial cancer. Oncotarget 9 : 5786-5796, 2018
41. Nie WB, Zhao LM, Guo R, Wang MX and Ye FG: Circular RNA circ-NT5C2 acts as a potential novel biomarker for prognosis of osteosarcoma. Eur Rev Med Pharmacol Sci 22: 6239-6244, 2018.

42. Wang L, Du ZG, Huang H, Li FS, Li GS and Xu SN: Circ-0003998 promotes cell proliferative ability and invasiveness by binding to miR-197-3p in osteosarcoma. Eur Rev Med Pharmacol Sci 23: 10638-10646, 2019.

43. Dong W, Bi J, Liu H, Yan D, He Q, Zhou Q, Wang Q, Xie R, Su Y, Yang M, et al: Circular RNA ACVR2A suppresses bladder cancer cells proliferation and metastasis through miR-626/EYA4 axis. Mol Cancer 18: 95, 2019.

44. Yao Y, Zuo J and Wei Y: Targeting of TRX2 by miR-330-3p in melanoma inhibits proliferation. Biomed Pharmacother 107: 1020-1029, 2018

45. Tang T, Yang L, Cao Y, Wang M, Zhang S, Gong Z, Xiong F, He Y, Zhou Y, Liao Q, et al: LncRNA AATBC regulates Pinin to promote metastasis in nasopharyngeal carcinoma. Mol Oncol 14: 2251-2270, 2020.

46. Wei Z, Ma W, Qi X, Zhu X, Wang Y, Xu Z, Luo J, Wang D, Guo W, Li X, et al: Pinin facilitated proliferation and metastasis of colorectal cancer through activating EGFR/ERK signaling pathway. Oncotarget 7: 29429-29439, 2016.

47. Alpatov R, Munguba GC, Caton P, Joo JH, Shi Y, Shi Y, Hunt ME and Sugrue SP: Nuclear speckle-associated protein Pnn/DRS binds to the transcriptional corepressor CtBP and relieves CtBP-mediated repression of the E-cadherin gene. Mol Cell Biol 24: 10223-10235, 2004.

48. Joo JH, Alpatov R, Munguba GC, Jackson MR, Hunt ME and Sugrue SP: Reduction of Pnn by RNAi induces loss of cell-cell adhesion between human corneal epithelial cells. Mol Vision 11: $133-142,2005$

49. Ritter J and Bielack SS: Osteosarcoma. Ann Oncol 21 (Suppl 7): vii320-vii325, 2010. 